\title{
Carbon cycling of Chinese forests: From carbon storage, dynamics to models
}

\author{
HE JinSheng ${ }^{1,2}$ \\ ${ }^{1}$ Key Laboratory of Adaptation and Evolution of Plateau Biota, Northwest Institute of Plateau Biology, Chinese Academy of Sciences, \\ Xining 810008, China; \\ ${ }^{2}$ Department of Ecology, and Key Laboratory for Earth Surface Processes of Ministry of Education, Peking University, Beijing 100871, China
}

Received January 5, 2012; accepted January 23, 2012

Citation: He J S. Carbon cycling of Chinese forests: From carbon storage, dynamics to models. Sci China Life Sci, 2012, 55: 188-190, doi: 10.1007/ s11427-012-4285-z

With a coverage of $30 \%$ of the Earth's land area, forest biomes play an important role in global carbon $(\mathrm{C})$ cycling and $\mathrm{C}$ management [1]. There are two main reasons for this. First, a huge amount of $\mathrm{C}$ is stored in forest live biomass, detritus, and soil organic matter; this accounts for $45 \%$ of the $\mathrm{C}$ storage in the global terrestrial ecosystem. Second, when forest ecosystems are destroyed or converted to other ecosystems, much of the $\mathrm{C}$ stored is released from the ecosystems; this is an important source of atmospheric $\mathrm{CO}_{2}$. Therefore, research into forest biomass and productivity has gained considerable attention in recent decades. From the International Biological Program (IBP) in the 1960s [2] to the recent global reassessment of the $\mathrm{C}$ balance of ecosystems [3], forest $\mathrm{C}$ cycling has long been a key issue.

Recently, based on field measurements, three papers [4-6] in SCIENCE CHINA Life Sciences have focused on forest productivity and $\mathrm{C}$ storage of tropical rain forest, subtropical evergreen broad-leaved forest, temperate deciduous broad-leaved forest, and temperate coniferous forest across East China. These studies provide solid data for the ongoing national carbon inventory campaign supported by the Strategic Priority Research Program of the Chinese Academy of Sciences, which was launched in 2011.

Chen et al. [4] estimated biomass $\mathrm{C}$ densities and their changes from 1983 to 2005 in mountain tropical rainforests of Jianfengling in Hainan Island, based on monitoring data

email: jshe@pku.edu.cn from forest permanent plots and biomass allometric relationships. Their results show that biomass ranges from 397.1 to $502.4 \mathrm{t} \mathrm{hm}^{-2}$, with an average of $453 \mathrm{t} \mathrm{hm}^{-2}$, and accordingly the biomass carbon density ranges from 201.4 to $254.9 \mathrm{t} \mathrm{C} \mathrm{hm}^{-2}$, with an average of $230.8 \mathrm{t} \mathrm{C} \mathrm{hm}^{-2}$. During 1983-2005, the mountain tropical rainforests in Jianfengling exhibited a $\mathrm{C}$ sink, and the average sink size was $0.56 \mathrm{t} \mathrm{C} \mathrm{hm}^{-2} \mathrm{a}^{-1}$. These results offer direct evidence that Chinese tropical forests represent a $\mathrm{C}$ sink.

Yang et al. [5] first established biomass allometric models for component tree species in evergreen broad-leaved forest in Tiantong, Zhejiang Province, and from these models, the community biomass of Schima superb-Castanopsis carlesii forest was calculated. The results show that the mean total biomass of 52-year-old S. superb-C. carlesii forest is $225.3 \mathrm{t} \mathrm{hm}^{-2}$, equating to about $101.4 \mathrm{t} \mathrm{C} \mathrm{hm}^{-2}$, with $28.0 \%$ of the total biomass being stored underground. In their study, the biomass of subtropical evergreen broad-leaved forests in different regions of China is also compared.

Zhang et al. [6] investigated the patterns of carbon density and carbon allocation in six typical temperate forests on Mt Maoer, Heilongjiang Province. These authors found that the total ecosystem carbon density varies from 186.9 to $349.2 \mathrm{t} \mathrm{C} \mathrm{hm}^{-2}$ over the six forest types. The $\mathrm{C}$ densities of vegetation, detritus, and soil account for $40 \%$, 3\%, and $57 \%$ of the total $\mathrm{C}$ densities, respectively. The root:shoot ratios range from $22.0 \%$ to $28.3 \%$ and small root (diameter $<5$ 
$\mathrm{mm}$ ) biomass range from 0.95 to $3.24 \mathrm{t} \mathrm{C} \mathrm{hm}^{-2}$. This is another detailed case study on $\mathrm{C}$ cycling of temperate forest ecosystems following studies on Mt Dongling, Beijing [7].

Based on these results and related studies on forest $\mathrm{C}$ cycling $[7,8]$, it is possible to combine these data and show the variations of forest biomass with latitude in East China (Figure 1). Overall, tropical and subtropical forests have higher biomass than other forests, with a decreasing trend with latitude. However, the linear relationship is not simple, with large variations in tropical and subtropical regions. This indicates that the environmental parameters directly associated with latitude, such as temperature and precipitation, have limited explanatory power for forest biomass. Consequently, the question arises as to what biotic and abiotic factors determine forest biomass. There is no easy an- swer to this question.

Generally, it is acknowledged that the determinants of community $\mathrm{C}$ input rate (i.e., primary production) are soil moisture, temperature and soil nutrient conditions. In the short term, the direct influencing factors are temperature, atmospheric $\mathrm{CO}_{2}$ concentration, leaf nitrogen content, leaf area index, and the length of growing season [9]. In the long term at the community successional scale, however, the final determinants are soil parent material, climate, topography, biota and development time, namely, five relatively independent-state factors [10]. The biomass of a community is the net accumulation of the balance of $\mathrm{C}$ input and output in the background of long-term community succession, therefore is ultimately determined by the five independentstate factors. In the short term, community dynamics and
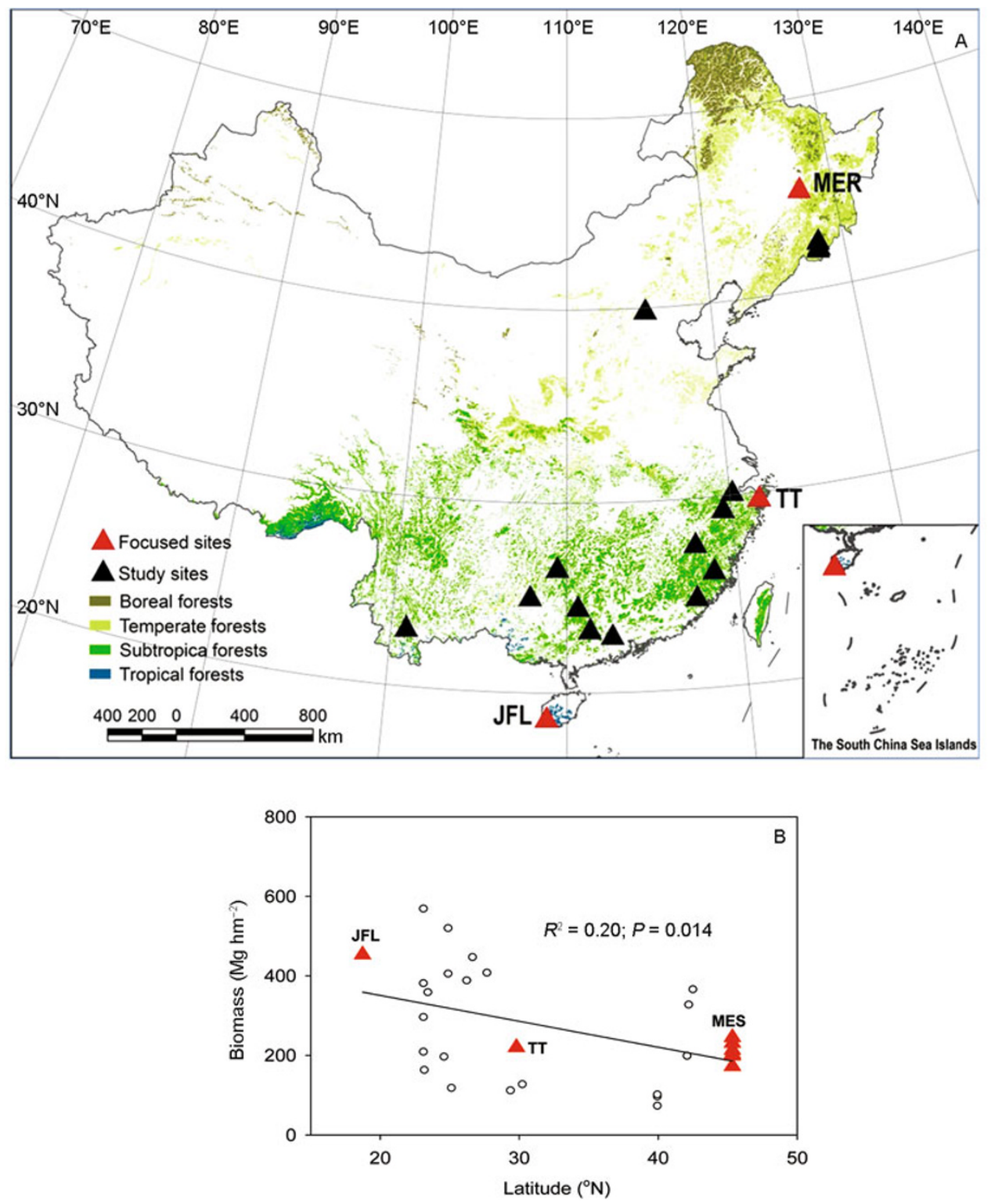

Figure 1 Research sites in the special issue entitled "Carbon budget in East Asian ecosystems" (Vol. 53, 2010) in SCIENCE CHINA Life Sciences (A), and variations of forest biomass along the latitudinal gradient (B). JFL, Jianfengling, Hainan Island; TT, Tiantong, Zhejiang Province; MES, Mt Maoer, Heilongjiang Province. 
management are the important determinants.

Interestingly, it was found recently that there is a good linear relationship between forest biomass and forest mean height. Based on a global database of forest biomass, Fang et al. [11] found that aboveground biomass is proportional to forest mean height in the closed forest (with the equation: biomass (in $\mathrm{Mg} \mathrm{hm}^{-2}$ ) $=10.63 \times$ height (in $\mathrm{m}$ )), and concluded that aboveground biomass per forest spatial unit area was a fixed value. Theoretically, this finding expands the law of constant final yield of plant populations $[12,13]$ to that of a forest community, and practically it is promising to develop a new method for large-scale forest biomass estimation. Recently, using a database of forest biomass and productivity in China, Hui et al. [14] further proved that forest height is better than diameter at breast height (DHB) for prediction of forest biomass and production. In grassland ecosystems, however, the relationship between community height and biomass seems to be more complex because community height is related to root:shoot ratio rather than community biomass or production [15].

For forest ecosystems, the patterns of $\mathrm{C}$ stocks have been addressed clearly, with a well-developed database of biomass and intensive field sampling sites. However, it is still premature to develop $\mathrm{C}$ cycling models for most forest ecosystems, which need long-term field monitoring to obtain not only data on $\mathrm{C}$ stocks, but also $\mathrm{C}$ fluxes among different pools. At present, measurement of $\mathrm{C}$ cycling faces two difficulties: (i) a large pool vs. small fluxes - it is very difficult to detect accurately the $\mathrm{C}$ changes and fluxes between pools in a short time; and (ii) the spatial heterogeneity - the variances among sampling plots are often larger than fluxes between C pools. Currently, some detailed C-cycling models have been developed for forest ecosystems, e.g., temperate oak forest in Hubbard Brook, New Hampshire [16] and Pseudotsuga-Tsuga coniferous forest of Wind River Experimental Forest in Washington State, USA [17]. In contrast, we still lack a detailed and representative model of $\mathrm{C}$ cycling in China, although some very preliminary models exist [7].

As in other research disciplines, study of $\mathrm{C}$ cycling follows the development path from pattern to mechanism, which in this case is from $\mathrm{C}$ storage, to dynamics, then detailed models. An important task of future research efforts is to establish reference sites for $\mathrm{C}$ cycling studies in zonal and typical forest ecosystems and forest plantations, to develop a detailed C-cycling model for each site, and finally to construct a nationwide $\mathrm{C}$-cycling reference-site system with which to calibrate the $\mathrm{C}$ models. With this knowledge, it is not a big step to achieve accurate assessment and prediction of ecosystem $\mathrm{C}$ cycling across China.

1 Fahey T J, Woodbury P B, Battles J J, et al. Forest carbon storage: ecology, management, and policy. Front Ecol Environ, 2010, 8: 245-252

2 Lieth H, Whittaker R H, eds. Primary Productivity of the Biosphere. Berlin-Heidelberg-New York: Springer Verlag, 1975

3 Pan Y D, Birdsey R A, Fang J Y, et al. A large and persistent carbon sink in the world's forests. Science, 2011, 333: 988-993

4 Chen D X, Li Y D, Liu H P, et al. Biomass and carbon dynamics of a tropical mountain rain forest in China. Sci China Life Sci, 2010, 53: 798-810

5 Yang T H, Song K, Da L J, et al. The biomass and aboveground net primary productivity of Schima superba-Castanopsis carlesii forests in east China. Sci China Life Sci, 2010, 53: 811-821

6 Zhang Q Z, Wang C K. Carbon density and distribution of six Chinese temperate forests. Sci China Life Sci, 2010, 53: 831-840

7 Fang J Y, Liu G H, Zhu B, et al. Carbon budgets of three temperate forest ecosystems in Mt. Dongling, Beijing, China. Sci China Ser D-Earth Sci, 2007, 50: 92-101

8 Zhu B, Wang X P, Fang J Y, et al. Altitudinal changes in carbon storage of temperate forests on Mt Changbai, Northeast China. J Plant Res, 2010, 123: 439-452

9 Chapin F S III, Matson P A, Mooney H. Principles of Terrestrial Ecosystem Ecology. New York: Springer-Verlag, 2002

10 Jenny H. Factors of soil formation. New York: McGraw-Hill, 1941

11 Fang J Y, Brown S, Tang Y H, et al. Overestimated biomass carbon pools of the northern mid- and high latitude forests. Climatic Change, 2006, 74: 355-368

12 Kira T, Ogawa H, Shinozaki K. Intraspecific competition among higher plants. I. Competition-density-yield interrelationships in regularly dispersed populations. J Polytech Inst Osaka City Univ, 1953, 4: 1-16

13 Weiner J, Freckleton R P. Constant final yield. Ann Rev Ecol Evol Syst, 2010, 41: 173-192

14 Hui D, Wang J, Le X, et al. Influences of biotic and abiotic factors on the relationship between tree productivity and biomass in China. Forest Ecol Manag, 2012, 264: 72-80

15 Li Y H, Luo T X, Lu Q. Plant height as a simple predictor of the root to shoot ratio: Evidence from alpine grasslands on the Tibetan Plateau. J Veget Sci, 2008, 19: 245-252

16 Fahey T J, Siccama T G, Driscoll C T, et al. The biogeochemistry of carbon at Hubbard Brook. Biogeochemistry, 2005, 75: 109-176

17 Harmon M E, Bible K, Ryan M G, et al. Production, respiration, and overall carbon balance in an old-growth Pseudotsuga-Tsuga forest ecosystem. Ecosystems, 2004, 7: 498-512

Open Access This article is distributed under the terms of the Creative Commons Attribution License which permits any use, distribution, and reproduction in any medium, provided the original author(s) and source are credited. 